IJIS

8,1

2

\title{
Editorial
}

\section{In a world of change}

Welcome to the new International Journal of Innovation Science. We have worked hard at the Journal for the past eight years and have now moved to a new publisher. We will be updating the paper submission system in the next few weeks as well as the cover. You should expect to see changes in the format of the papers as well as just about every other aspect of the layout. What will remain the same is the dedication to innovation that our readers have come to expect.

As our readers know, innovation is quickly becoming an accepted academic discipline throughout the world. As an academic discipline, the need to publish papers on the science of innovation is greater than ever. With our new partnership with Emerald Publishing, we feel like we are finally in a position to actively become a part of the success for a community in need of publishing outlets. Although we only publish quarterly, we now receive around 125 papers per year, of which only around 20 are published. As additional papers come in and our impact factor increases, authors who submit to the IJIS will find the value to be ever greater in the coming years. We hope you will become a part of the movement and submit your original research to the journal.

Getting to our current issue, we have another outstanding issue this quarter. Our first paper is the third of three papers submitted by Dennis Stauffer. Mr Stauffer's paper continues to describe his research on personal innovativeness as a predictor of entrepreneurial value. His first two papers dealt with Valuable Novelty Theory (IIIS, Volume 7, Number 3) and the Innovation Mindset (IIIS, Volume 7, Number 4). This paper builds on the last two papers to develop a measurement of what it takes to be a great entrepreneur. This series of papers is particularly important because of the need to identify candidates (entrepreneurs) who would most likely be successful in an entrepreneurial venture. Long and the short of the study is that people with higher innovativeness index scores tend to also be more successful as entrepreneurs. Accordingly, funders or corporate executives should be excited, as this tool can help not only to predict the success of a potential funding candidate but also for corporate executives looking for the right person to head up a new initiative.

The second paper in the edition is an important one to the International Association of Innovation Professionals. Dana Landry, the Vice President of Certification Programs, makes the case for the importance of professional certification in the science of innovation. Just as this publication acts to highlight the qualifications of the individual writers and researchers, so does certification. As Mr Landry cites Polidoro (2005):

Certifications are relevant social cues that assist decision making under uncertainty. When an employer wants to know if a potential candidate has the necessary competencies and knowledge to perform a certain set of tasks they often look to education, experience, certificates and/or certifications. When experience or education is similar, the presence or absence of a certificate or certification can make the difference about who will be hired.

This also holds true for papers and research performed in the area in question. In reality, any time two equally qualified candidates are being compared; it is the one who has done the

International Journal of Innovation Science

Vol. 8 No. 1, 2016

pp. $2-3$

c) Emerald Group Publishing Limited

1757-2223

DOI 10.1108/IJIS-03-2016-006 extra that is expected to win out. Beyond the obvious benefit to this organization, he also makes a very strong global case for the development and application of certifications.

Our third paper is another multi-paper series edition. Soroush Maghsoudi is a doctoral student who is researching and writing about innovation in building and 
construction. He points out some of the points that are often missed by people who only study innovation as it relates to high tech. A misconception is that innovation only takes place in Silicon Valley, but the informed know that Silicon Valley is only the best at public relations. His work in innovation evaluation, as related to the development of small- to medium-sized construction projects, supported by extensive data is well worth the read by anyone who does not understand that industries such as construction, oil and gas and consumer packaged goods are at least as innovative as software. Has software enabled much of this? Yes. However, as I imagine anyone in the construction industry will tell you, buying a better hammer does not necessary translate into a more innovative way to build. The tools and techniques that his findings discuss could be a tremendous value to anyone wanting to innovate in their building projects.

Our fourth paper is one for students of the world, who address difficult and unusual problems generated by unusual situations. Specifically, Shubing Qui and colleagues perform a study on the development of farmer-entrepreneurs in relocation settlements in China. The goal is to reduce the prevalence of poverty setting in on the relocated farmers by teaching them new skills that can be valuable in a modern economy.

In our final paper of this edition, Zang Yon'an and colleagues write about China's regional science and innovation policy. What is particularly interesting about this paper is the proposal to classify innovation policy into four "types", described as authoritative, guiding, urgent and periodical, and how looking at several measurements can identify the type. The measurements identified are function type, intensity, resource supply, funding level and funding effectiveness. In this, writers experience, while I have never seriously considered the factors that effect the success of an innovation policy, this is a very good attempt to lay the groundwork for understanding public policy, as it relates to success of science parks and publically financed innovation efforts.

As I have previously mentioned, as innovation professionals, we are extremely excited about the opportunities afforded us through the partnership with Emerald. We hope you enjoy this issue and continue to support us as we move to the next phase in what will someday be a great global journal.

\section{Brett E. Trusko Editor-in-Chief Texas A\&M University, College Station, Texas, USA and International Association of Innovation Professionals}

\section{Reference}

Polidoro, F., Jr (2013), “The competitive implications of certification: the effects of scientific and regulatory certifications on entries into new technical fields", Academy of Management Journal, Vol. 56 No. 2, pp. 597-627. 